\title{
Experimental Study of Darrieus-Savonius Water Turbine with Deflector: Effect of Deflector on the Performance
}

\author{
Kaprawi Sahim, Kadafi Ihtisan, Dyos Santoso, and Riman Sipahutar \\ Mechanical Engineering, Sriwijaya University, Jalan Raya Palembang-Prabumulih Km 32, Indralaya 30662, Indonesia \\ Correspondence should be addressed to Kaprawi Sahim; kaprawis@yahoo.com
}

Received 21 October 2013; Accepted 8 January 2014; Published 20 February 2014

Academic Editor: Tariq Iqbal

Copyright (C) 2014 Kaprawi Sahim et al. This is an open access article distributed under the Creative Commons Attribution License, which permits unrestricted use, distribution, and reproduction in any medium, provided the original work is properly cited.

The reverse force on the returning blade of a water turbine can be reduced by setting a deflector on the returning blade side of a rotor. The deflector configuration can also concentrate the flow which passes through the rotor so that the torque and the power of turbine can be considerably increased. The placing of Savonius in Darrieus rotor is carried out by setting the Savonius bucket in Darrieus rotor at the same axis. The combination of these rotors is also called a Darrieus-Savonius turbine. This rotor can improve torque of turbine. Experiments are conducted in an irrigation canal to find the performance characteristics of presence of deflector and Savonius rotor in Darrieus-Savonius turbine. Results conclude that the single deflector plate placed on returning blade side increases the torque and power coefficient. The presence of Savonius rotor increases the torque at a lower speed, but the power coefficient decreases. The torque and power coefficient characteristics depend on the aspect ratio of Savonius rotor.

\section{Introduction}

Exploitation of renewable energies has been intensified to meet the electricity needs when there is a potential source of hydropower. This kind of energies will decrease the environmental problems of pollution. River's flow, canal flow, irrigation flow, and tidal current still have many difficulties to be extracted optimally. This is due to the low efficiency of the energy technology in which the water turbines used for stream flow have to be developed. One of the turbines commonly used is a helical type which gives the efficiency of $35 \%$ [1]. However, if a large capacity of water flows, generating power depends on taking lots of flow rate into the turbine.

Different designs of water current turbines are available for the extraction of energy from the river water or canals. Based on the alignment of the rotor axis with respect to water flow, two generic classes exist. They are horizontal and vertical axis turbine. The commonly used vertical axis turbines are Darrieus, Gorlov, and Savonius turbine. Helical blade and Darrieus straight blade water turbine are commonly suitable for extraction of kinetic energy of flowing water. Helical blades have a smaller rate of pulsation [2] and more favorable starting characteristics than straight blades [3], but the blades are very difficult to be constructed than the straight blade.
The turbine system should be a simple structure and with a good reliability to fulfil the power generation so that one can construct by itself like for small-scale applications of local production of electricity [4]. The tip speed ratio (TSR) of Darrieus turbine is high and that is why it rotates much faster. The Darrieus type has a cost-advantage due to the simple structure. Installing the Darrieus turbine in a narrow canal with small clearance will increase the efficiency [5]. Savonius turbine is another type of simple one. This turbine has the advantage of self-starting torque, but the efficiency and the operation speed are lower. Savonius design uses a rotor that is formed by cutting the flattener cylinder into two halves along the central plane and then moving the two semicylindrical surfaces sideways along the cutting plane so that the crosssection resembled the letter "S" [6].

The efficiency of Savonius turbine can be increased by making configuration of single stage, two-stage, and threestage rotor. These configurations have been tested in a water channel as it was conducted by Khan et al. [7]. The use of two deflector plates can increase significantly the power coefficient of modified Savonius rotor as studied experimentally by Golecha et al. [8],where one deflector is placed on the returning blade side and the other is placed on the outside of the advancing blade side. To improve the starting 
torque of the Darrieus turbine used for power generation, a Darrieus-Savonius turbine, composed of a Darrieus turbine and Savonius rotor, has been experimentally tested in an open channel. The Darrieus-Savonius turbine has a higher torque at a lower speed than the solo Darrieus turbine, but the efficiency is lower than the Darrieus rotor regardless of Savonius bucket orientation (attachment angle). In DarrieusSavonius turbine, the best attachment angle of Savonius rotor is placed perpendicularly to the Darrieus rotor. The operational tip speed ratio of solo Savonius turbine is less than unity and the solo Darrieus is greater than unity. The combined turbine of Darrieus-Savonius has the operational tip speed ratio greater than unity [9]. In Darrieus-Savonius rotor, the bucket of semielliptic cylinders is used to improve the torque at a low speed; however, the rotation and efficiency are still lower than solo Darrieus turbine [10]. The usage of guide vane increases the performance of wind turbine of Darrieus type as it was tested by Takao et al. [11].

From the literature survey, the effects of deflector and the bucket size on the performance have not been clarified so far. It is the reason, in the present paper, we propose to observe experimentally the impact of the Darrieus-Savonius turbine using a deflector plate and variable bucket dimensions on the performance which is represented by limits of torque and power coefficient. The combined Darrieus-Savonius turbine consists of Darrieus and Savonius turbine in which the Savonius rotor is placed on the middle of Darrieus rotor on the same shaft. Savonius water turbine and cross-flow water turbine can be improved by setting deflector around the rotors because the deflector in upstream of the rotor can increase torque and power coefficient.

\section{Experimental Setup and Procedure}

In Darrieus-Savonius turbine, the Darrieus turbine has been used as a main device and the Savonius turbine as a startup device. They are permanently attached to the same axis. The Savonius turbine is composed of two semicircular buckets. Figure 1 shows the setting of a deflector plate to the combined rotor. The deflector plate placed upstream to the fluid flow on the returning blade side acts as an obstacle to the flow coming towards the returning blade. This reduces the negative or reverse torque on the returning blade. Experiments are conducted for two positions of the deflector plate on the returning blade side of the combined rotor. In the first position, deflector is set at $\beta=0^{\circ}$ (without deflector) and in second position, the deflector is set at $\beta=9^{\circ}$. The deflector plate has length of $100 \mathrm{~cm}$. Setting the second angle is to obtain the height of the deflector $h=(1 / 2) R$. The gap between rotor blade and end plate of the deflector was about $40 \mathrm{~mm}$. Figure 2 gives the dimension of the blade and bucket. The tested Darrieus rotor with the diameter of $d_{\mathrm{D}}=400 \mathrm{~mm}$ has two straight blades with a chord length of $C=125 \mathrm{~mm}$ and length of $L_{\mathrm{D}}=600 \mathrm{~mm}$. We use blade profile of NACA 0015 for the reason of small drag when compared to blades of higher thickness. The Darrieus-Savonius rotor has also two Savonius buckets with the diameter of a semicircular cylinder $d_{\mathrm{S}}$ and length $L_{\mathrm{S}}$.

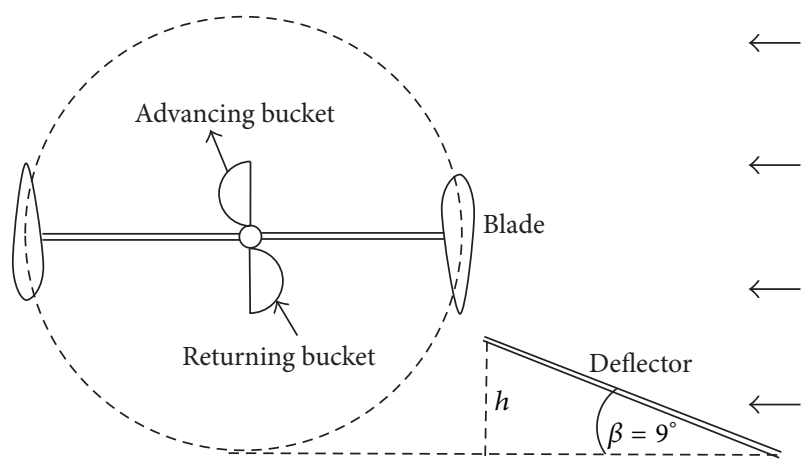

Figure 1: Darrieus-Savonius rotor.

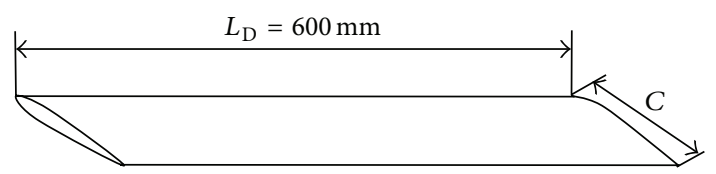

(a) Blade

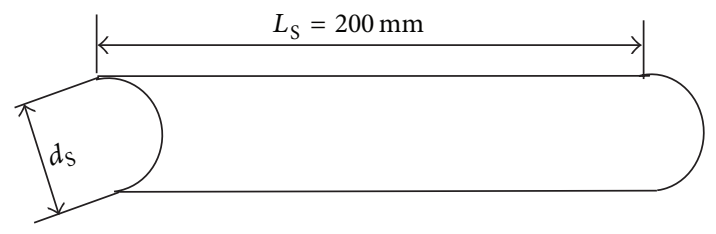

(b) Semicircular Bucket

Figure 2: Geometrical blade and bucket.

One of the purposes of the study is to reveal the influence of a swept area of Savonius bucket. For that reason, we chose only two buckets of diameter $d_{\mathrm{S}}=40 \mathrm{~mm}$ and $63 \mathrm{~mm}$ in Darrieus-Savonius turbine to be tested. The aspect ratio of Savonius rotor is defined by a ratio of the length of bucket and the total width or diameter of two buckets. In this case, the total diameter of buckets is twice the diameter of each bucket. The above dimensions of the bucket give the aspect ratio of $A_{\mathrm{r}}=2.5$ and 1.58. It is noted that higher aspect ratio represents a smaller swept area (smaller $d_{\mathrm{S}}$ ). The bucket is made of polyvinyl chloride (PVC) material and the blade of Darrieus rotor was made of wood with smooth surface. In this study, solidity of Darrieus rotor is kept constant at 0.2 and it is calculated by the following expression:

$$
\sigma=\frac{C \cdot B}{\pi \cdot d_{\mathrm{D}}}
$$

The turbine axis of diameter $14 \mathrm{~mm}$ is held by two ball bearings.

The torque of the rotor was measured by a rope brake dynamometer with nylon rope of diameter $2 \mathrm{~mm}$. The water turbine was first revolved without any loads and at this condition, the revolution was maximum. The loads were gradually added to the revolution by adding a certain mass on weighing pan; then the rotation and the load on spring scale were measured until the water turbine was completely stopped (overload). The mass on weighing pan was measured by digital scale with accuracy 500 gram/0.01 gram, while 


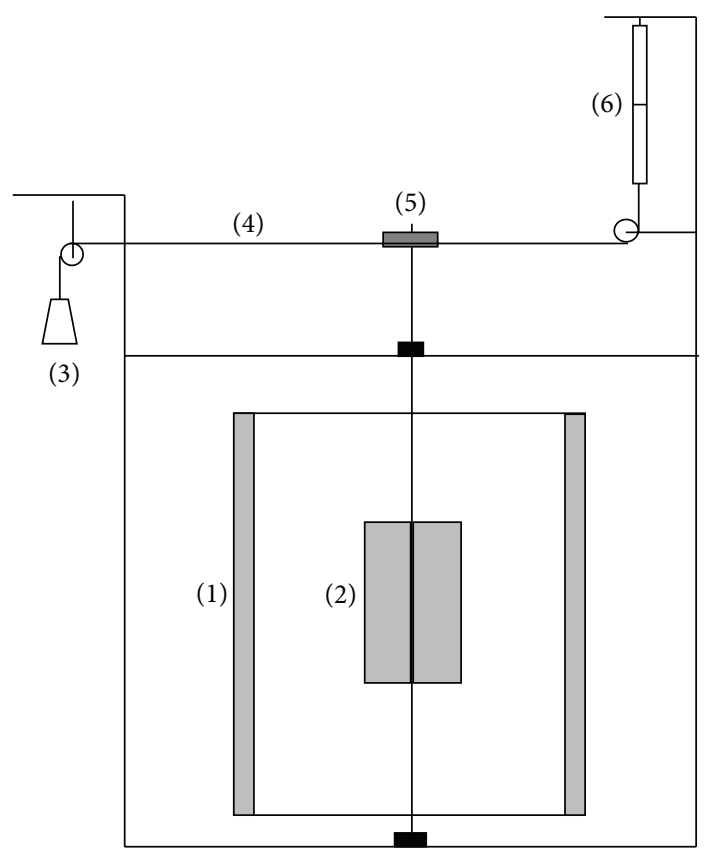
(1) Darrieus blade
(2) Savonius bucket
(4) Rope
(3) Weighing fan
(5) Brake wheel
(6) Tubular spring scale

FIgURE 3: Schematic diagram of the test setup for the DarrieusSavonius turbine.

the rotational speed of the rotor was measured using a laser tachometer. The same procedures of measurement were used for the other configurations of the combined turbine. The current meter flowatch FL-03 with accuracy $2 \%$ was used to measure the free stream velocity. The tubular spring scale of range $0-50 \mathrm{~N}$ was used to measure the force (see Figure 3).

The rotational speed of the rotor is represented by dimensionless parameter tip speed ratio (TSR or $\lambda$ ). TSR is calculated by the following relation:

$$
\lambda=\frac{U}{V} .
$$

The effective torque, $T$, is calculated by

$$
T=g \cdot\left(F_{\mathrm{S}}-F_{\mathrm{W}}\right) \cdot\left(\frac{d_{b}+d_{\mathrm{r}}}{2}\right)[\mathrm{Nm}] .
$$

Torque coefficient is obtained from the following relation:

$$
C_{T}=\frac{T}{T_{i}},
$$

where $T_{i}$ is available torque; $T$ is effective torque.

The performance of the turbine is given by the power coefficient $C_{P}$ and torque coefficient $C_{T}$. These coefficients represent the produced energy of the turbine as part of the total water energy passing through the swept area of the turbine rotor. This area equals the frontal area of the turbine given by the height times the diameter. As the blades perform a complete circle, the blades in the downstream part of

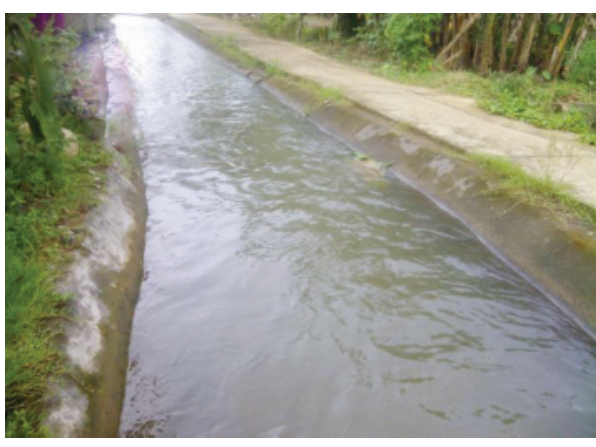

FIGURE 4: Irrigation canal for turbine test.

the turbine are influenced by the wake resulting from the upstream blades. The available power in water flow is given by

$$
P=\frac{1}{2} \rho A V^{3} .
$$

Power coefficient is then defined by

$$
C_{P}=\frac{P_{\mathrm{S}}}{P} .
$$

The aspect ratio of Savonius bucket is defined by the relation as follows [6]:

$$
A_{t}=\frac{L_{\mathrm{S}}}{D_{\mathrm{S}}}
$$

The experiments were carried out in an irrigation canal in Lubuk Linggau, Indonesia. The water velocity of the free stream is constant at $0.71 \mathrm{~m} / \mathrm{s}$ due to the irrigation system of overflow in the main river. Water flow is coming from river in which the flow is diverted into the irrigation canal by using a sluice gate. The canal has $2.2 \mathrm{~m}$ width and $0.8 \mathrm{~m}$ depth (Figure 4). The turbine rotor was set in the middle of the canal to avoid the effect of the boundary layer of flow near the canal wall.

\section{Results and Discussion}

Figure 5 shows the influence of aspect ratio of Savonius rotors on coefficient of torque and power of Darrieus-Savonius turbine without deflector, which are compared to the solo Darrieus rotor. The torque of coefficient of solo Darrieus turbine has a peak value of 0.133 at $\lambda=1.06$, while the Darrieus-Savonius turbine with $A_{t}=2.5$ has a torque coefficient of 0.126 at $\lambda=0.88$. This combined turbine shows a lower torque coefficient than solo Darrieus rotor and when the aspect ratio decreases (smaller swept areas), the coefficient becomes much lower. On the left part of the curves, there are no data points because of the overload of turbine with higher load and the rotor stops to run.

The performance of Darrieus-Savonius rotor is also shown by Figure 5(b) which presents the relation between the power coefficients and tip speed ratio. It is observed that solo Darrieus rotor has peak power coefficient of 


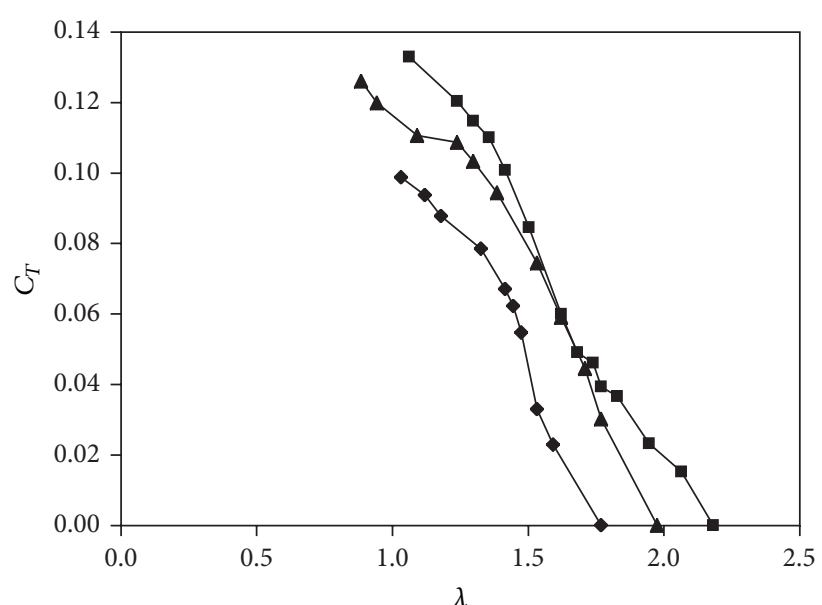

- Solo Darrieus

\ Darrieus-Savonius turbine with $A_{t}=2.5$

- Darrieus-Savonius turbine with $A_{t}=1.58$

(a) Torque coefficient

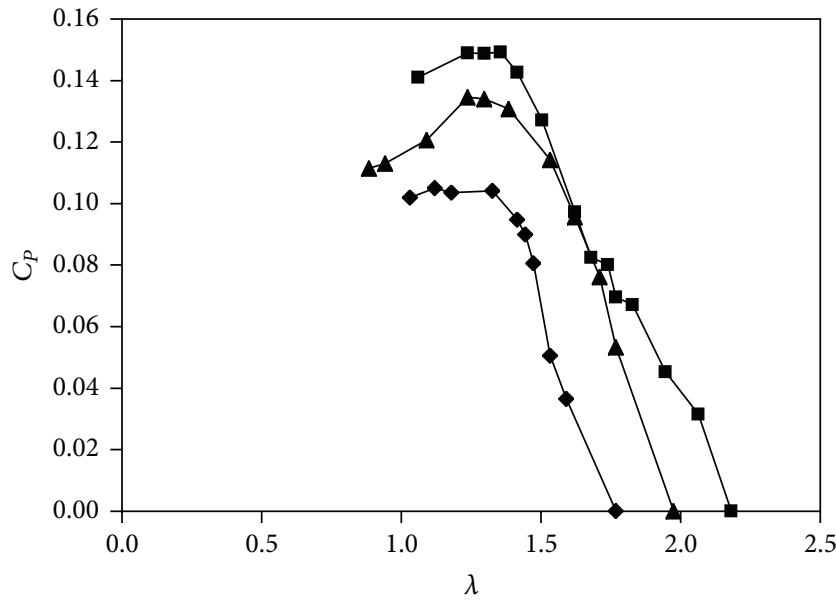

- Solo Darrieus

- Darrieus-Savonius turbine with $A_{t}=2.5$

- Darrieus-Savonius turbine with $A_{t}=1.58$

(b) Power coefficient

FIGURE 5: Characteristics performance of Darrieus-Savonius turbine without deflector.

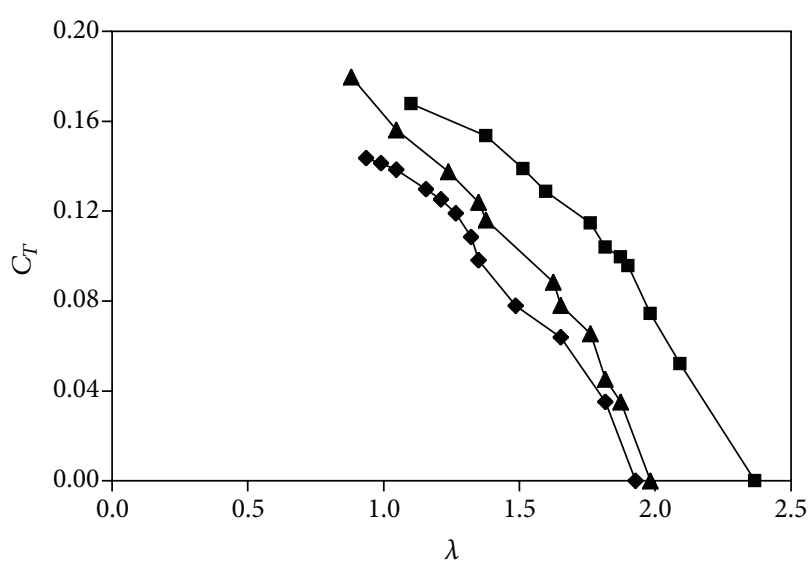

- Solo Darrieus

- Darrieus-Savonius turbine with $A_{t}=2.5$

- Darrieus-Savonius turbine with $A_{t}=1.58$

(a) Torque coefficient

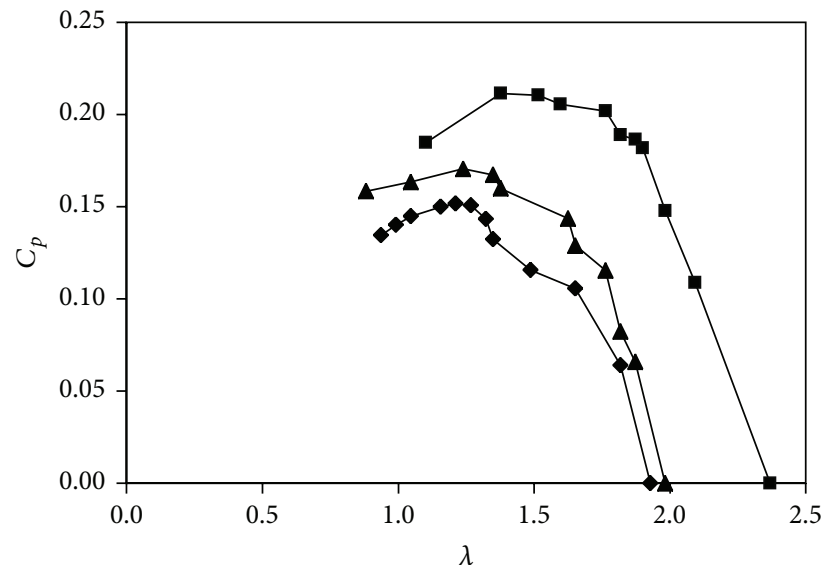

- Solo Darrieus

- Darrieus-Savonius turbine with $A_{t}=2.5$

- Darrieus-Savonius turbine with $A_{t}=1.58$

(b) Power coefficient

FIGURE 6: Characteristic performance of Darrieus-Savonius turbine with deflector.

0.149 when compared to the Darrieus-Savonius rotor. For combined turbine with $A_{\mathrm{r}}=2.5$ (smaller frontal area of the bucket), the peak power coefficient is 0.134 and for a smaller aspect ratio, the coefficient is much lower. Both types of the combined turbines have a lower coefficient of power than the solo Darrieus. It is obvious that the bigger the Savonius bucket in combined turbine, the smaller the characteristics of performance, and the bigger bucket makes a higher drag force and reverse force because the shear stress becomes considerably significant. The convex surface side of the bucket may experience high skin friction drag and the concave side may experience the induced drag force. These parameters cause the deceleration of turbine rotation. The profile of torque and power coefficient shifts to the left part which shows that the rotation of Darrieus-Savonius turbine is smaller than the solo Darrieus turbine.

The performances of the turbines with deflector are presented in Figure 6. The torque profiles are similar to the torque of turbine without deflector (Figure 5(a)) in which the solo Darrieus turbine has a higher torque for high rotation. We observe that using the deflector, all turbines have higher torque compared to turbines without deflector. At peak condition, the increase is considerably significant and it is about 30\% for solo Darrieus and 40\% for Darrieus-Savonius 
turbine with $A_{t}=2.5$. It seems that at a lower tip speed ratio, the torque of Darrieus-Savonius rotor with $A_{t}=2.5$ is higher than that of solo Darrieus. There is a little improvement of turbine torque at a lower speed.

The increase of the torque coefficient is followed by the increase of the power coefficient as shown by Figure 6(b). At condition of peak value, the power coefficient increases. For solo Darrieus turbine, the increase achieves $41 \%$ and for Darrieus-Savonius turbine with $A_{t}=2.5$, the increase is about $30 \%$ or the maximum value increases from 0.149 to 0.211 for solo Darrieus turbine and from 0.134 to 0.171 for Darrieus-Savonius turbine with $A_{t}=2.5$.

We observe further, the presence of the deflector has a very little influence upon the tip speed ratio of DarrieusSavonius and solo Darrieus turbine as shown by Figures 5 and 6. In fact, the number of rotations of turbine with deflector increased but when it is transformed into the dimensionless tip speed ratio. It becomes little changes in variation of $\lambda$. By setting the deflector at a certain angle, the free stream velocity increased due to concentration of flow and this makes the increase of turbine rotation so that it may be constant as stated by the definition of the tip speed ratio. The presence of deflector, the coefficient of torque, and coefficient of power increase significantly as shown by Figures 5 and 6 .

We observe all configurations of Darrieus-Savonius turbine containing Savonius rotor and that the rotational speed becomes lower than solo Darrieus rotor. The characteristic performances decrease from the solo Darrieus performance. It may be caused by geometric of a bucket of Savonius rotor. The higher bucket dimensions decrease the rotor performance and it is due to higher skin friction drag of viscous flow water on the outer surface of the convex bucket in all complete rotations of the rotor. The other part, the concave side of bucket section, produces induced drag when rotating at returning side.

\section{Conclusions}

From the above discussions, it is concluded that installing of Savonius in Darrieus rotor without deflector makes the Darrieus-Savonius rotor have lower performance characteristics than solo Darrieus rotor, but the torque has a little increase. By setting a deflector plate in upstream rotor of Darrieus-Savonius turbine, the power coefficient characteristics and torque coefficient characteristics increase significantly. In Darrieus-Savonius, the aspect ratio of Savonius buckets affects the turbine performances because a higher performance is obtained for a higher aspect ratio.

\section{Abbreviations}

$A_{t}:$ Aspect ratio

B: Number of blades

$C$ : Chord length of blade $(\mathrm{m})$

$C_{p}$ : Power coefficient

$C_{T}$ : Torque coefficient

$d_{p}$ : Diameter of brake wheel $(\mathrm{m})$

$d_{\mathrm{D}}$ : Diameter of Darrieus rotor $(\mathrm{m})$ $d_{\mathrm{r}}:$ Rope diameter $(\mathrm{m})$

$d_{\mathrm{S}}$ : Diameter of semicircular bucket $(\mathrm{m})$

$D_{\mathrm{S}}$ : Total diameter of Savonius rotor $\left(=2 d_{\mathrm{S}}\right)$

$F_{S}$ : Load on spring scale (kgf)

$F_{\mathrm{W}}$ : Load on weighing pan (kgf)

$g: \quad$ Gravitation force $\left(\mathrm{m} / \mathrm{s}^{2}\right)$

$h$ : Height of deflector position (m)

$L_{\mathrm{D}}$ : Length of Darrieus blade or rotor $(\mathrm{m})$

$L_{\mathrm{S}}$ : Length of Savonius bucket or rotor $(\mathrm{m})$

$P: \quad$ Water power (Watt)

$P_{\mathrm{S}}$ : Shaft power (Watt)

$R: \quad$ Radius of Darrieus rotor $(\mathrm{m})$

$T: \quad$ Torque $(\mathrm{Nm})$

$U:$ Tangential velocity of Darrieus rotor $(\mathrm{m} / \mathrm{s})$

$V: \quad$ Free stream velocity $(\mathrm{m} / \mathrm{s})$.

Greek Symbols

$\beta$ : Deflector angle $\left(^{\circ}\right)$

$\lambda$ : Tip Speed Ratio

$\sigma$ : Solidity.

\section{Conflict of Interests}

The authors declare that there is no conflict of interests regarding the publication of this paper.

\section{Acknowledgment}

This paper is supported by the BOPTN Fund of Sriwijaya University.

\section{References}

[1] A. N. Gorban', A. M. Gorlov, and V. M. Silantyev, "Limits of the turbine efficiency for free fluid flow," Journal of Energy Resources Technology, vol. 123, no. 2-4, pp. 311-317, 2001.

[2] J. D. Winchester, S. D. Quayle, and S. D. ", “Torque ripple and variable blade force: a comparison of darrieus and gorlov-type turbines for tidal stream energy conversion," in Proceedings of the 8th European Wave and Tidal Energy Conference, Uppsala, Sweden, 2009.

[3] M. Shiono, K. Suzuki, and S. Kiho, "Output characteristics of darrieus water turbine with helical blades for tidal current generations," in Proceedings of the 12th International Offshore and Polar Engineering Conference, pp. 859-864, Kitakyushu, Japan, May 2002.

[4] J.-L. Menet, "A double-step Savonius rotor for local production of electricity: a design study," Renewable Energy, vol. 29, no. 11, pp. 1843-1862, 2004.

[5] D. Matsushita, K. Okuma, S. Watanabe, and S. Furukawa, "Simplified structure of ducted Darrieus type hydro turbine with narrow intake for extra low head hydropower utilization," Journal of Fluid Science and Technology, vol. 3, no. 3, 2008.

[6] M. J. Alam and M. T. Iqbal, "A low cut-in speed marine current turbine," Journal of Ocean Technology, vol. 5, no. 4, pp. 49-62, 2010.

[7] M. N. I. Khan, M. Tariq Iqbal, M. Hinchey, and V. Masek, "Performance of savonius rotor as a water current turbine," Journal of Ocean Technology, vol. 4, no. 2, pp. 71-83, 2009. 
[8] K. Golecha, T. I. Eldho, and S. V. Prabhu, "Investigation on the performance of a modified savonius water turbine with single and two deflector plates," in Proceedings of the 11th Asian International Conference on Fluid Machinery, IIT Madras, Chennai, India, November 2011.

[9] Y. Kyozuka, "An experimental study on the Darrieus-Savonius turbine for the tidal current power generation," Journal of Fluid Science and Technology, vol. 3, no. 2, 2008.

[10] S. Kaprawi, D. Santoso, and A. Radentan, "Performance of combined water turbine with semielliptic section of the savonius rotor," International Journal of Rotating Machinery, vol. 2013, Article ID 985943, 5 pages, 2013.

[11] M. Takao, H. Kuma, T. Maeda, Y. Kamada, M. Oki, and A. And Minoda, "A straight-bladed vertical axis wind turbine with a directed guide vane row-effect of guide vane geometry on the performance," Journal of Thermal Science, vol. 18, no. 1, pp. 5457, 2009. 

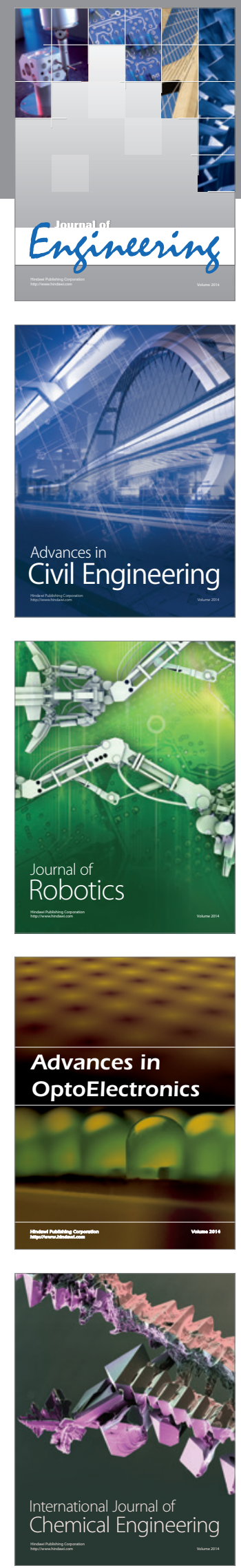

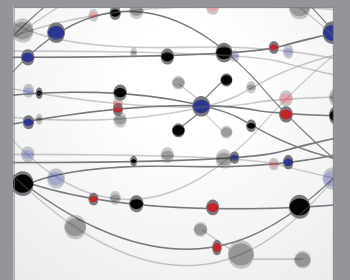

The Scientific World Journal
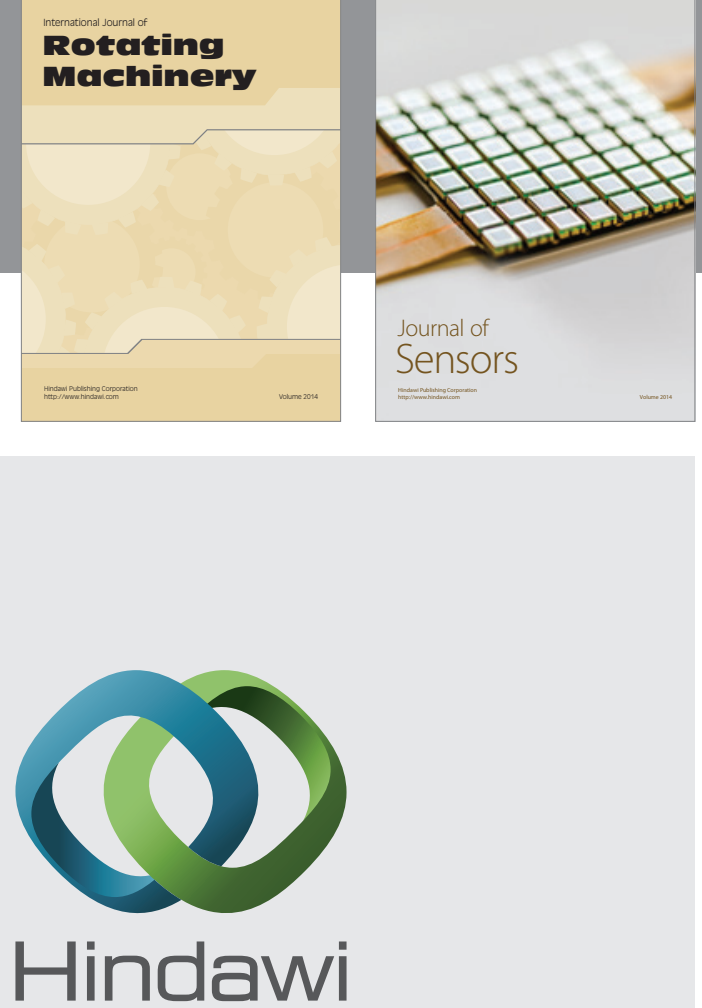

Submit your manuscripts at http://www.hindawi.com
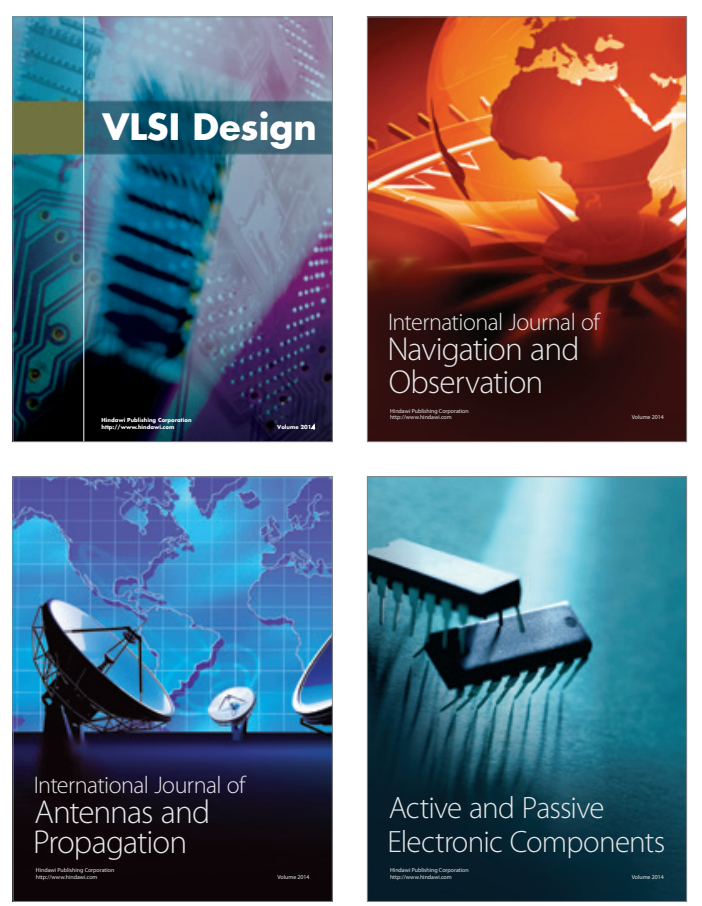
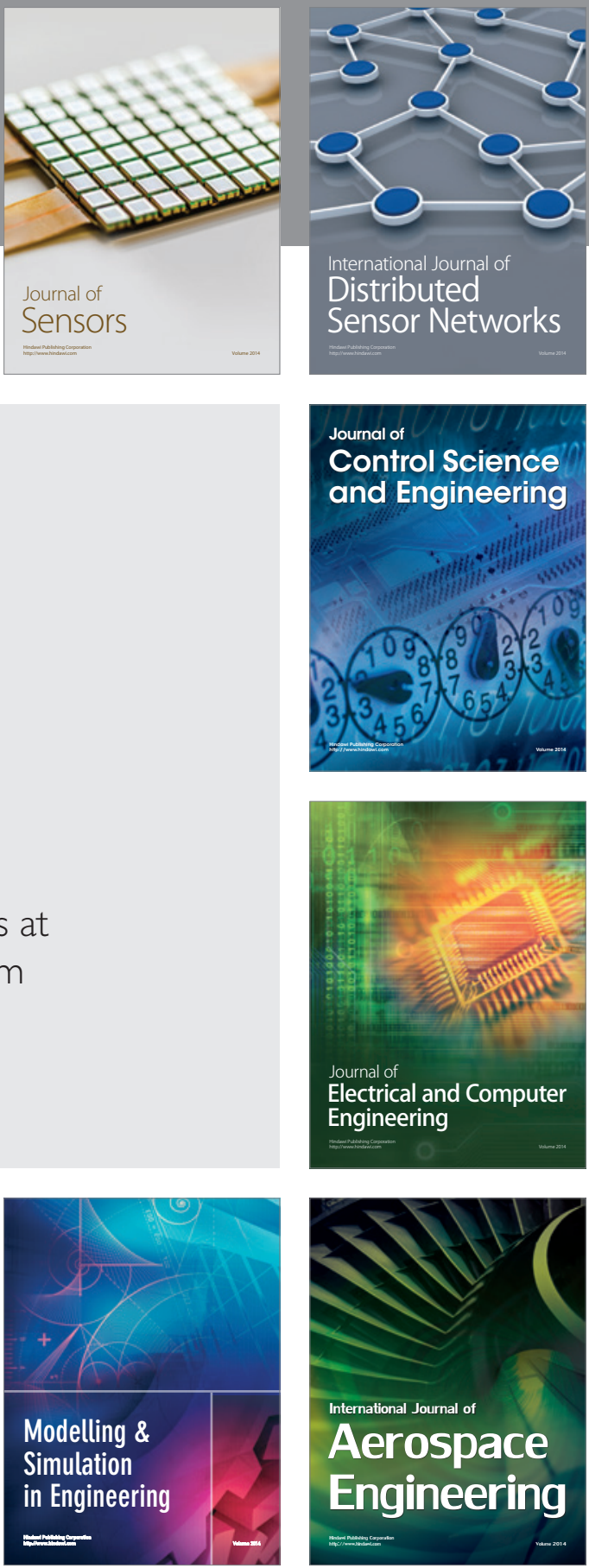

Journal of

Control Science

and Engineering
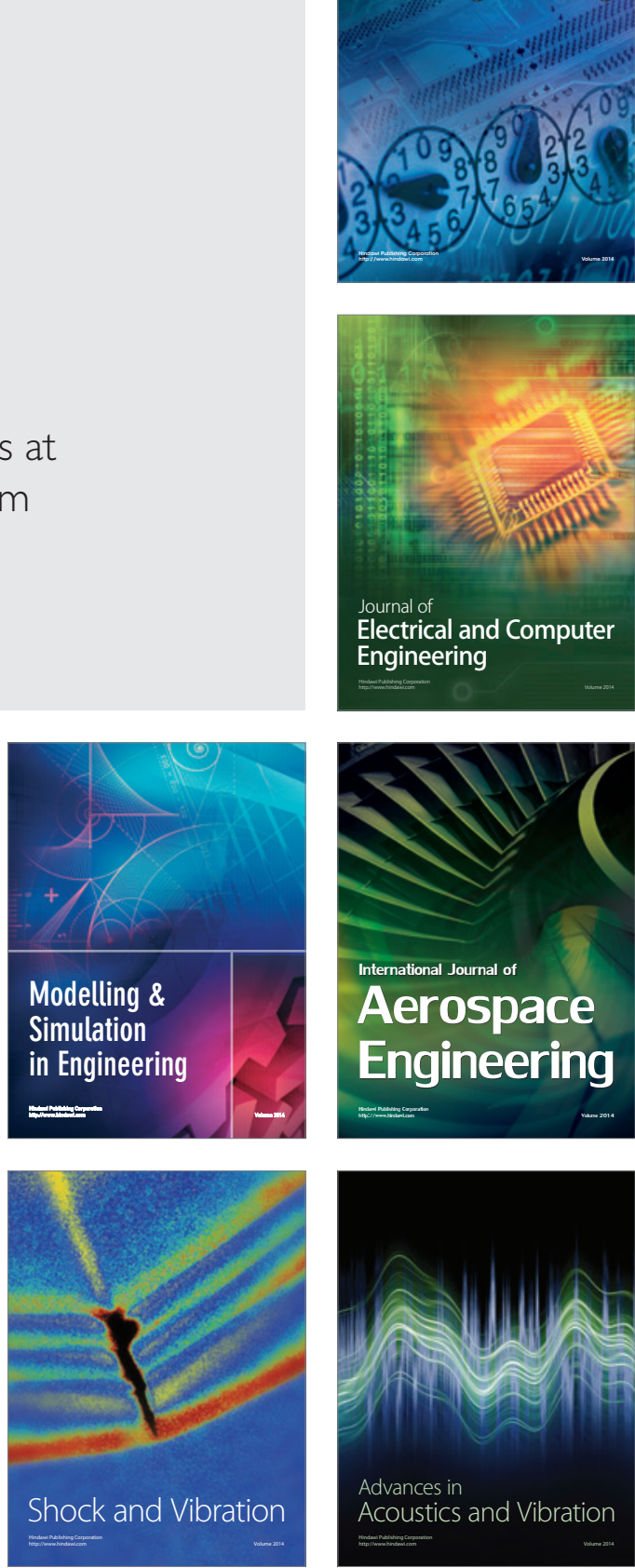